\title{
Watershed Management a Tool to Address Climate Change
}

\section{Keshar Man Sthapit ${ }^{1}$}

\begin{abstract}
Climate change and its effects on the water resources therefore also, livelihood is a major global concern. Water scarcity is already a major problem for the world poor, and changes in rainfall and temperature associated with climate change will likely make this worse. This indicates that efficient and effective management of the available water becomes essential for overall development, improving livelihoods and maintaining food sufficiency.

Watershed management carries number of activities managing water resource to address the ever increasing water resource problems. Therefore, watershed management could be one of the tools to cope with climate change managing scarce water resource. This paper describes some of the watershed activities dealing with water resource management.
\end{abstract}

Key Words: Watershed management, Climate change, Run off, Degraded land rehabilitation

\section{Introduction}

Ever increasing population made the water more precious than ever. Every year the water turnover on earth involves $577,000 \mathrm{~km}^{3}$ of water. It is the water that evaporates from the oceanic surface $\left(502,800 \mathrm{~km}^{3}\right)$ and from land $\left(74,200 \mathrm{~km}^{3}\right)$. The same water amount falls as atmospheric precipitation (on the ocean $458,000 \mathrm{~km}^{3}$ and on land $119,000 \mathrm{~km}^{3}$ ). The difference between precipitation and evaporation from land surface $\left(119,000-74,200=44,800 \mathrm{~km}^{3} /\right.$ year) represents the total runoff of Earth's rivers $\left(42,600 \mathrm{~km}^{3} /\right.$ year), and a direct groundwater runoff to the ocean $\left(2200 \mathrm{~km}^{3} /\right.$ year $)$. These are the principal sources of fresh water to supply life necessities and man's economic activities. ${ }^{2}$

Climate change and its effects on the water resources therefore, livelihood has been a major concern. The average surface temperature of the earth has increased between $0.3^{\circ} \mathrm{C}$ and $0.6^{\circ} \mathrm{C}$ over the past hundred years and the global mean temperature is expected to increase between 1.4 to $5.8^{\circ} \mathrm{C}$ over the next hundred years ${ }^{3}$. (Figure 1)

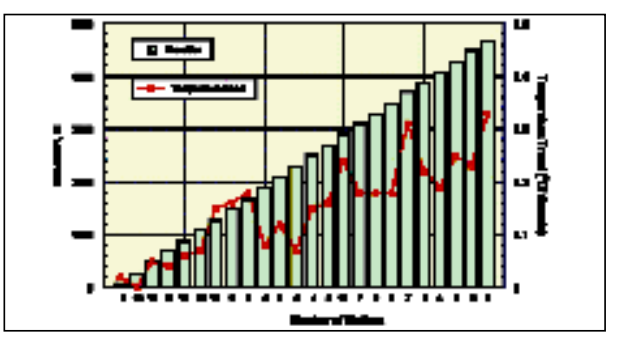

Figure 1: Dependence of warming on elevation on the Tibetan Plateau. ${ }^{4}$

\footnotetext{
Author is currently working with ICIMOD as Watershed Specialist. View expressed in this article is solely of the author and not of the ICIMOD. ksthapit@icimod.org

2 State hydrological Institute, 1999. World Water resources and Their Use Join SHI/UNESCO product. St. Petersburg.

3 Bajracharya, S. R. , P. K. Mool, and B. R. Shrestha, 2007. Impact of Climate Change on Himalayan Glaciers and Glacial Lakes Case Studies on GLOF and Associated Hazards in Nepal and Bhutan, ICIMOD.

4 Liu, X.; Chen, B. (2000) 'Climate Warming in the Tibetan Plateau during Recent Climate Warming in Western China'. In quaternary Sciences, 26 (5): 762-771. As cited in ICIMOD, 2007. The melting Himalayas: Regional Challenges and Local Impacts of Climate Change on Mountain Ecosystems and Livelihoods.
} 
On the Indian subcontinent, temperatures are predicted to increase between 3.5 and $5.5^{\circ} \mathrm{C}$ by 2100. It is estimated that a $1^{\circ} \mathrm{C}$ rise in temperature will cause alpine glaciers worldwide to shrink as much as 40 per cent in area and more than 50 per cent in volume as compared to $1850^{5}$. As a result the snow area in the mountain is decreasing affecting the water availability in the rivers. This is more prominent in case of Himalayas (Figure 2).

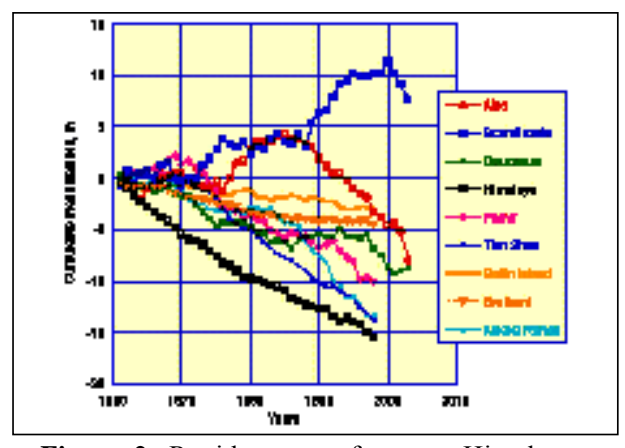

Figure 2: Rapid retreat of greater Himalayan glaciers in comparison to the global average. ${ }^{6}$

Rise in temperature will increase the evapo-transpiration and increase in extreme event of rainfall and temperature is causing more flood and drought. Water scarcity is already a major problem for the world poor, and changes in rainfall and temperature associated with climate change will likely make this worse. This indicates that efficient and effective management of the available water is essential for overall development, improving livelihoods and maintaining food sufficiency.

Managing water is best done in watersheds because watersheds are natural landscape units most appropriate to equate water balance, downstream impacts with upstream activities and to focus on process based studies on water, sediment and nutrient flow which help to a better understanding of complex systems and cumulative effects (Schreier, et al., 2006). And watershed management is a one of the tools to cope with climate change especially for managing scarce water resource.

\section{Watershed Management}

Watershed management is management of land, water and other natural resources on a sustainable basis. Watershed management carries out number of activities with an integrated approach addressing proper land use, protecting lands from all forms of degradation, building and maintaining soil fertility, conserving water for farm use, proper management of water for drainage, erosion control, production, flood protection, sediment reduction and increasing productivity from all land uses. To fulfill the watershed objectives, different Agronomic / Management, Vegetative, and Small Structural Conservation Techniques are packaged into different activities/measures. These measures may be broadly classified as Preventive, Rehabilitative, Conservation education and extension, and Income generating. Following are some rationales of watershed management activities generally implemented to address the water scarcity problems exaggerated by the climate change. However, this is not the exhaustive list of activities.

\footnotetext{
Intergovernmental Panel on Climate Change (IPCC), 2001. Third Assessment Report: Working Group II: Impacts, Adaptation and Vulnerability, p. 9. Oxford: Oxford University Press in WRI, UNDP, UNEP and the World Bank, 2005. World Resources 2005: The Wealth of the Poor: Managing Ecosystems to Fight Poverty. Washington DC: WRI.

${ }^{6}$ Dyurgerov, M.D.; Meier, M.F. (2005) Glaciers and Changing Earth System: A 2004 Snapshot, p 117. Boulder (Colorado): Institute of Arctic and Alpine Research, University of Colorado. As cited in ICIMOD, 2007. The melting Himalayas: Regional Challenges and Local Impacts of Climate Change on Mountain Ecosystems and Livelihoods.
} 


\section{Vegetative Measures}

Vegetative measures such as degraded land rehabilitation mainly through planting grass, tree and fruit sampling, hedgerows, agro-forestry mainly in degraded barren area is one major activity of watershed management. Vegetated watersheds have a "sponge effect". Forest soil, roots and litters act as a giant sponge, soaking up water from rain and runoff and releasing gradually over an extended period. ${ }^{7}$ Therefore, vegetated watersheds play a key role in the management of water resources mainly by improving water quality and flow regime. Following research finding also support this conclusion.

Critical analysis of Instantaneous Unit Hydrograph (IUH) in the hydrologic and sediment monitoring study carried in India indicated that ${ }^{8}$ :

- The rising limb of the IUH prior to treatment was very steep which indicates that water from the watershed rushed away within a short period of time whereas after treatment there was a delay in runoff.

- Recession limb of IUH lacked skewness prior to treatment whereas after treatment the same got eradicated. This indicates that there was a smooth flow after treatment period.

- The recession limb also revealed that after certain hours the flow of water was likely to discontinue from the watershed, whereas the post treatment scenario indicated that there was a continuous flow.

After treatment, the water flow is delayed and remains smooth which means it helps in reducing flood risk; a continuous flow also leads to an improvement in water flow regime. Similar analysis has been conducted for many other watersheds and it has been found that runoff peak and volume are reduced by $30-40 \%$ as compared to pre-treatment. This reveals that more water gets infiltrated into the soil profile resulting in a reduction of runoff peak and volume flow. The silt flow from the treated area has also reduced for the same quantum of runoff. Similarly, the sediment yield was reduced to $45 \%$ as compared to pre-treatment rate for the same amount of runoff.

\section{Protection of Water Source from Erosion}

Land use beyond its capability and without proper conservation measures enhances erosion in uplands and sedimentation downstream. One of the principles of watershed management is to use the land as per its capability or suitability. So that erosion therefore water pollution from sediment remains low. This helps to protect the water source such as springs, lakes/ ponds, and rivers and enhance their suitability for human use.

\footnotetext{
After FAO \& CIFOR, 2005. Forests and floods: Drowning in fiction or thriving on facts?. RAP Publication 2005/3. Forest Perspectives 2.

8 Honore, Guy 2002. Principles and Practices of Integrated Watershed Management in India. Published by IndoGerman Bilateral Project "Watershed Management", New Delhi.
} 


\section{Efficient use of Water}

Proper use of available water resource is one of the key strategies to address the world water scarcity. Watershed management considers different efficient technologies such as drip irrigation, water efficient conservation farming system such as system of rice intensification, etc.

\section{Drip Irrigation}

Drip irrigation is a method of watering plants by delivering drops of water in a controlled way to plant root zones of the crop. The system is made up of a water tank and a network of pipes with drippers at predetermined intervals. Drip irrigation allows slow and precise delivery of water around the root zone therefore it reduces water loss.

In Jhikhu Khola watershed, Kavre district (Nepal) farmers found that drip irrigation

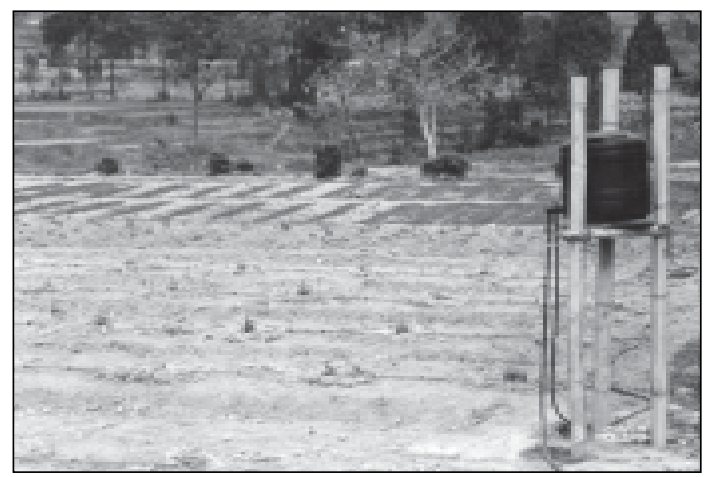

Drip irrigation system in use for growing bitter gourd saves about $60 \%$ of water and $50 \%$ labour force compared to the conventional method of using bucket irrigation. It also helps to mature the crop earlier. Due to the better water use efficiency drip irrigation helps to increase the area under vegetable cultivation and in a few cases to cultivate fallow land (after monsoon crops), which contributes to additional household income.

Drip irrigation system to cover an area of $80 \mathrm{~m}^{2}$ cost about NRs. 1400 (in 2008) and last for about 5 years. In 2004 in Jhikhu Khola watershed a farmer earned an extra income of NRs. 1000 growing bitter gourd by using drip in one season from $80 \mathrm{~m}^{2}$ of land.

\section{System of Rice Intensification (SRI) ${ }^{9,10}$}

SRI is an agronomic practice of growing rice differently than conventional flooded rice growing method. In this system, 8-12 day-old 2leaf seedlings are planted at a wide spacing (generally $25 \mathrm{~cm}$ x $25 \mathrm{~cm}$ or even wider). Only a small amount of water is applied when the field is prepared for transplanting, and the fields do not require continuous flooding except during the flowering stage. If the land starts cracking

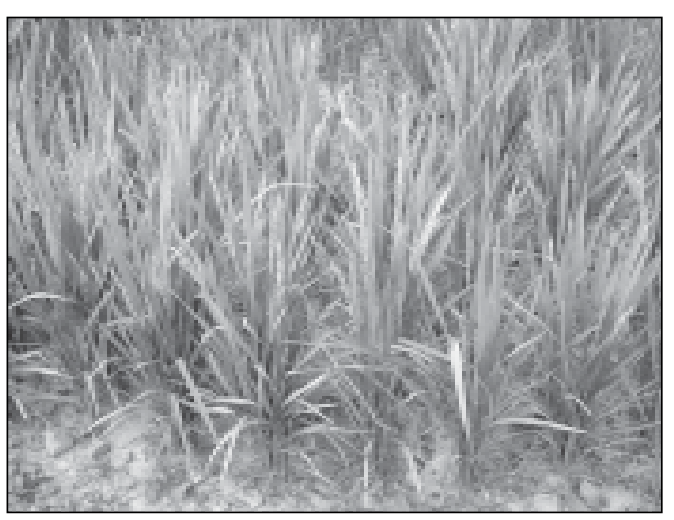

SRI: Wide spacing planting with less water

9 ICIMOD, 2007, Good Practices in watershed management:

Lessons Learned in the Mid-Hills of Nepal. International Centre for Integrated Mountain development, Kathmandu.

10 Natural Resource Management - approaches and technologies in Nepal: NEPCAT fact sheets (2008).

http://books.icimod.org/index.php/search/subject/3 
due to drying, light irrigation is required to moisten the soil. Alternate dry and moist soil conditions improve aeration thus helping the plants to grow vigorously.

In Jhikhu Khola watershed, farmers found that SRI requires 50 to $75 \%$ less water, $75 \%$ less of seeds, $50 \%$ less labor for transplanting; and 50-60\% less labor for irrigation than traditional method. At the same time there is about $40-50 \%$ increase in grain and $20-25 \%$ increase in biomass production. This was considered as advantageous for a smallholder farmer.

\section{Water Harvesting}

Water harvesting is a collection and storage of water during excess period and use when required to address the water scarcity problems. Under water harvesting, conservation pond and roof water harvest are most demanded activities.

\section{Conservation Pond}

Conservation pond is an indigenous practice to store wastewater and / or run-off water during excess rain to reduce erosion as well as irrigate the crop during critically stressed period. The primary concern of a conservation pond is to manage water wisely for soil conservation and watershed management purposes. However, its use can be extended to serve multiple purposes: aahale (buffalo bathing), irrigation, fisheries, entertainment and so on as required.

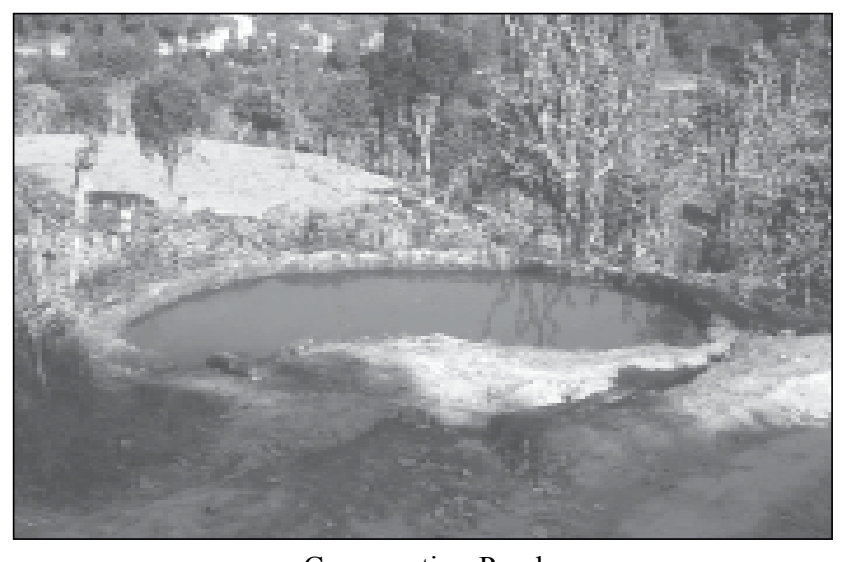

Conservation Pond Conservation pond (non-lined) plays crucial role in recharging ground water improving soil moisture through regulating infiltration, which increases the production. Depression of the conservation pond will have better moisture condition and can be used for growing crops during the dry period.

\section{Roof Rainwater Harvesting}

It is to collect the rainwater from roof and store it in a jar mainly for household use. It is popular constructing ferro-cement jars and it is found appropriate for addressing water scarcity and reducing women workload. In Jhikhu Khola (JK) watershed (middle mountain), women including young girls fetch $68 \%$ quantity of water. People in JK spend about 33 minutes for one trip (5min - 120min) to fetch 1 gagri (15 liter) of water. With the construction of roof water harvesting jar, it takes only about 5 minutes (Sharma, Chiranjivi, 2001) to fetch 1 gagri (15 liters) of water. That means for each fetching of water about 27 minutes of time especially for women will be saved.

Analysis indicated that roof water harvesting from a roof area of $20 \mathrm{~m}^{2}$ could fulfill all water needs of a family size of 5-6 for the months of July and August, whereas for May, June and 
September it could fulfill only 44,78 and 60 $\%$ of its total water demand, respectively.

One analysis indicated that on average 20 $\mathrm{m}^{2}$ of roof water harvest saved about 528 hours for family size of 5-6. In addition, the use of rainwater during the monsoon season for drinking and other household chores is leading to better health and sanitation.

The total cost of one jar (2000 liters capacity) and gutter system ranges between

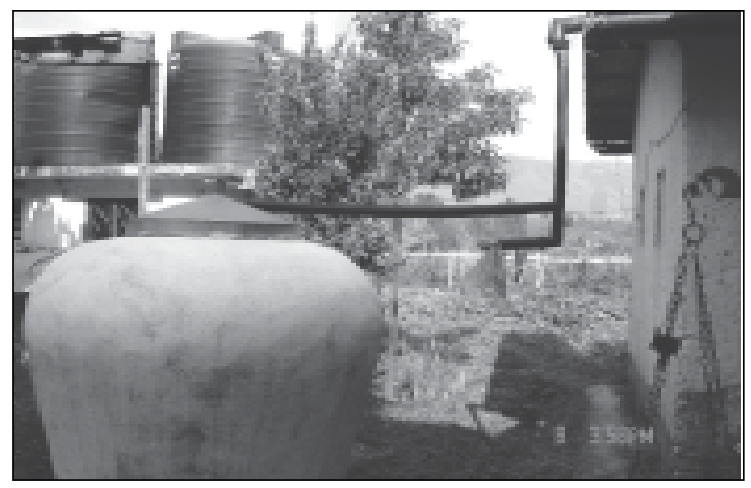

Roof water harvesting using ferro cement jar (Jhikhu Khola, Nepal) NRs. 6,000 to 8,500 depending upon the distance of the construction site from the road head and the number of systems constructed in one locality.

\section{Conclusion}

Watershed management is a tool for the efficient and effective management of the scarce water resource available to the human being. Its extensive implementation becomes today's need and must be prioritized for the well being of the growing population to address growing water resource problem exaggerated by the climate change.

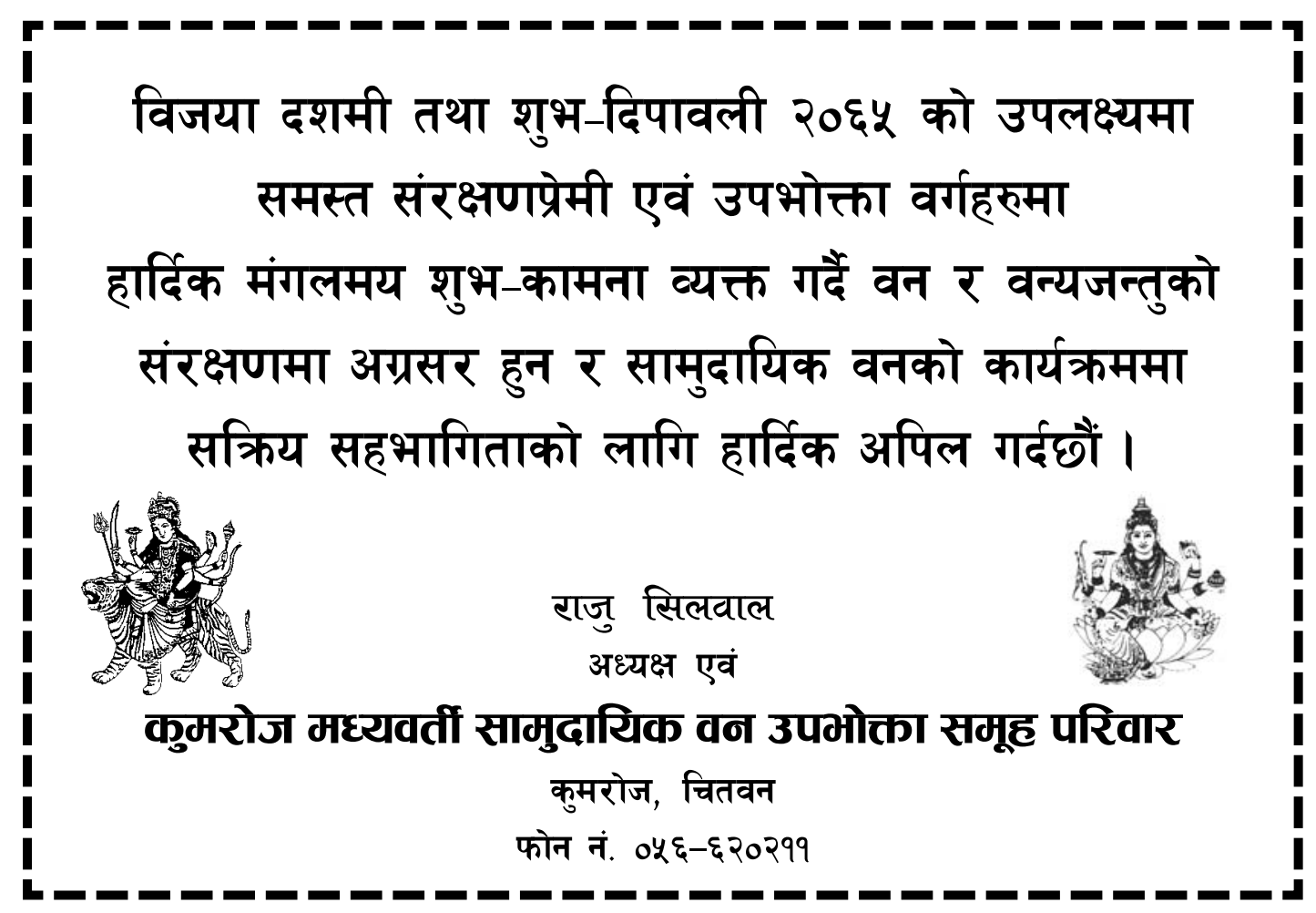

